Running head: Coping with incompatible identities

\title{
Coping with potentially incompatible identities: Accounts of religious, ethnic and sexual identities from British Pakistani men who identify as Muslim and gay
}

\author{
Rusi Jaspal and Marco Cinnirella \\ Royal Holloway, University of London
}

\begin{abstract}
This study explores how a group of young British Muslim gay men (BMGM) of Pakistani background in non-gay affirmative religious contexts understood and defined their sexual, religious and ethnic identities, focusing upon the negotiation and construction of these identities and particularly upon strategies employed for coping with identity threat. Twelve BMGM were interviewed using a semi-structured interview schedule. Transcripts were subjected to qualitative thematic analysis as described by Braun and Clarke (2006). The aim was to explore participants' lived experiences through the interpretive lens of identity process theory (Breakwell, 1986, 1992). Four superordinate themes are reported, entitled "I'm gay because..": Making sense of gay identity, "It's all about temptation": Invoking religious discourses to explain sexual identity, "Going against God": Fear of divine retribution, "It's easier to be gay here": External attributions and British national identity. The data suggest the existence of an additional identity principle, which is referred to as the psychological coherence principle. This motive represents the need to ensure a sense of coherence between existing identities, and we discuss how individuals may adopt strategies to deal with threats to the principle.
\end{abstract}

Keywords: identity processes; identity coherence; threat; gay identity; religion; ethnicity; Muslims

The impact of religion on the identities of lesbian, gay and bisexual (LGB) individuals has been explored in considerable depth by sociologists, although much of this work has focused upon Christianity (e.g. Thumma, 1991, Yip, 1997). The dominant view among many Muslims is that LGB identity is incompatible with Islam (Yip, 2007a). Research on homosexuality among Muslims in the West has been scarce, although in recent years, this lacuna in the literature has been paid some attention by sociologists (e.g. Yip, 2004a; Siraj, 2006). This work has discussed some of the challenges faced by British Muslim gay men (BMGM) as a result of their potentially conflicting sexual and religious identities. However, while the intersection of religious and sexual identities among Muslim gay men has been explored to some extent by sociologists, it remains under-explored by social psychologists. This is unfortunate given that social psychological theories of identity and identity threat may further elucidate the nature of identity threat as well as the coping strategies employed to counteract the threat. Moreover, given social psychology's long tradition of studying categorisation and identity processes (Verkuyten, 2005), it is argued that a social psychological perspective constitutes an important contribution to this under-explored area. While our empirical focus here is on the identities of BMGM of Pakistani background, some of our observations speak to broader and important theoretical issues of identity threat and multiple identification. 


\section{Islam and homosexuality}

It has been argued that Islam gives 'hegemonic status to heterosexuality' (Yip, 2004b, p. 297). Moreover, Islamic holy scripture (the Koran), Islamic law (Shari'ah) and the verbal teachings of the Prophet Mohammed (Ahadith) outlaw homosexuality (Bouhdiba, 1998). Therefore, it is unsurprising that social representations of homosexuality remain negative among many Muslims (Green \& Numrich, 2001). Furthermore, it is reasonable to assume that the cultural processes of heteronormativity and compulsory heterosexuality are acutely active in Islamic religious contexts (Boellstorff, 2005; Kligerman, 2007). Interestingly, it has been argued that in many Muslim communities homosexuality among young men is often overlooked provided one avoids any public recognition of one's sexuality and fulfils social and religious obligations such as marriage (Murray, 1997b). However, among Muslims in the West homosexuality is perhaps less readily 'denied' in this way but rather it is viewed as a symptom of 'Westernization' (Duran, 1993, p. 186), representing the 'moral decadence of the sexual host society' (Yip, 2004b, p. 297).

\section{Coping with stigma}

Given the generally negative social representations associated with homosexuality in Islam outlined above, it is perhaps reasonable to assume that many BMGM may fear the prospect of discrimination and prejudice from their religious community if they reveal their sexual identities. 'Coming out' as gay may therefore pose a risk of rejection by the ingroup and the positioning of the gay Muslim man as an ingroup 'black sheep' (Markes, Yzerbyt \& Leyens, 1988). Yip (2007a) argues that some BMGM may discard religious identity as a dissonance resolution strategy if they are unable to reconcile it with their sexual identity. A similar strategy was manifested by some participants in a sociological study exploring Cypriot gay men's accounts of cultural and sexual identity; individuals were said to disidentify with their ethnic group due to the stigma attached to homosexuality (Phellas, 2005). Social psychologists have identified the possibility of psychological self-removal from positions which pose a threat to identity (e.g. Tajfel, 1978; Breakwell, 1986; Vugt \& Hart, 2004). However, since religion is said to be a very important (and often the over-arching 'core') identity for many British Muslims (Jacobson, 1997; Jaspal \& Coyle, 2010), it is perhaps unlikely that the 'exit option' will constitute a desirable psychological option for many BMGM.

It has also been suggested that BMGM may compartmentalise their sexual and religious identities in order to deal with the antagonistic relationship between them (Yip, 2004b). An example of this is that a BMGM might de-emphasise his gay identity when in the mosque so that this identity has less psychological salience, but conversely at a gay festival, for instance, he is likely to de-emphasise his religious identity. The notion of compartmentalisation has also been identified by psychologists as a strategy for managing their multiple (and possibly conflicting) identities (Breakwell, 1986; Coyle \& Rafalin, 2000; Roccas \& Brewer, 2002). As a short term coping strategy, this has the psychological advantage of avoiding the intrapsychic conflicts and difficulties associated with multiple and potentially incompatible identities (Baumeister, 1986; Harter \& Monsour, 1992). However, since Islam constitutes more than just a religious identity but rather a 'meaning system' for many Muslims (Silberman, 2005), it may not be possible for all BMGM to draw boundaries around the threatening additions to the identity structure (Breakwell, 1986). Thus, for many BMGM religion is likely to inform their life narratives and other identities. Furthermore, it is noted that as individuals realise that the abstract characteristics of their identities (e.g. values, beliefs) are not as compartmentalised and context-specific as assumed previously, steps will be made towards a form of 
identity integration (Phinney, 1993; Amiot et al., 2007). Consequently, it would be useful to gain an insight into the ways in which religious identity and gay identity are integrated into a compatible meaning system.

\section{Identity: threat and management}

Given the centrality of stigma and identity threat in BMGM experience, the theoretical approach to the analysis of the construction of sexual identity employed in this paper is derived from identity process theory (IPT; Breakwell, 1986, 1988, 1992, 1993, 2001). IPT proposes that the structure of identity should be conceptualised in terms of its content and value/ affect dimensions and that this structure is regulated by two universal processes, namely the assimilation-accommodation process and the evaluation process. The assimilation-accommodation process refers to the absorption of new information in the identity structure and of the adjustment which takes places in order for it to become part of the structure. The evaluation process confers meaning and value on the contents of identity.

Breakwell $(1986,1992)$ identifies four identity principles which guide these universal processes, namely continuity across time and situation, uniqueness or distinctiveness from others, feeling confident and in control of one's life and feelings of personal worth or social value. IPT refers to these, respectively, as continuity, distinctiveness, self-efficacy and self-esteem. Extending IPT, Vignoles and colleagues (Vignoles, Chryssochoou \& Breakwell, 2002; Vignoles, Regalia, Manzi, Golledge \& Scabini, 2006) have proposed two additional identity 'motives', namely belonging, which refers to the need to maintain feelings of closeness to and acceptance by other people, and meaning, which refers to the need to find significance and purpose in one's life. The theory suggests that when any of these identity principles are obstructed by changes in the social context, for instance, identity is threatened and the individual will engage in coping strategies to alleviate the threat. A coping strategy is defined as 'any activity, in thought or deed, which has as its goal the removal or modification of a threat to identity' (Breakwell, 1986, p. 78).

From the social identity tradition, optimal distinctiveness theory (Brewer, 1991), which proposes that individuals identify with social groups to satisfy opposing motives for distinctiveness and belonging, was identified as an additional potentially useful theoretical framework. It was hypothesised that individuals would seek to assert a sense of belonging to the religious group in response to possible repudiation of group membership (see Yip, 2005). Models of identity integration may also be useful. For instance, Amiot et al. (2007) have proposed a four-stage model of social identity development and integration, which explains the specific processes whereby social identities are developed intrapsychically and become integrated within the selfconcept temporally. The notion of identity integration (Benet-Martinez \& Haritatos, 2005; Cheng et al., 2008) suggests that the more an individual perceives their (social) identities as compatible the higher their level of identity integration will be. Conversely, the perception of two or more identities as in opposition to each other, perhaps because they represent values and norms which fundamentally contradict one another, signals a lower level of identity integration. Identity integration has been said to predict a variety of cognitive, behavioural and mental health outcomes, such as psychological well-being (Campbell, Assanand \& Di Paula, A., 2003; BenetMartinez, Lee \& Leu, 2006).

Clearly, the focus of these frameworks is primarily at the intergroup level since both are rooted within the social identity tradition. If social identity is defined as 'that part of the individual's self-concept which derives from his or her knowledge of membership to a social group (or groups)' (Tajfel, 1981, p. 255), it may be inaccurate to conceptualise gay identity among many BMGM in terms of a social 
identity but rather as an aspect of personal/ individual identity (Hitlin, 2003; Simon, 2004) or perhaps a 'self-attribute' (Harter \& Monsour, 1992). This is likely to be particularly applicable to BMGM in non-gay affirmative religious contexts. However, the aforementioned theoretical frameworks indicate that a lack of identity integration (e.g. religious and sexual identities) may be conducive to identity threat and thus low psychological well-being.

Although previous research has shown that some BMGM may be discovering ways of integrating their religious and sexual identities (Minwalla et al., 2005), this is likely to pose threats to identity, particularly at the level of continuity (Breakwell, 1986). IPT has already been employed to interpret the construction of gay identity (Coyle, 1991) and to 'inform' the analysis of British Jewish gay men's accounts of negotiating sexual, religious and cultural identities (Coyle \& Rafalin, 2000). IPT has also been used to understand the identity implications of coming out experiences (Markowe, 2002). These studies highlight the need for a broad, inclusive theory of identity threat, such as IPT, which identifies multiple identity principles and which provides scope for the exploration of intrapsychic, not just interpersonal and intergroup, processes. It is primarily the intrapsychic level at which there is potential for conflict and distress resulting from the lack of 'self-coherence' and from the awareness of one's conflicting identities (Higgins, 1991; Harter \& Monsour, 1992). Moreover, important life changes (e.g. sexual self-disclosure), which may call for the integration or reconciliation of multiple identities (e.g. sexual, religious and ethnic), may result in identity conflict (Benet-Martinez \& Haritatos, 2005) and are thus likely to require the use of coping strategies (Amiot et al., 2007), many of which are accounted for by IPT. This research will also demonstrate how some of the identity principles highlighted by IPT interact with one another, which remains an important lacuna in IPT research and theorising.

The notion of identity threat is likely to be much more relevant to participants of the present study than those of previous studies carried out in this field. This is because much contemporary research on LGB identity among British Muslims (Siraj, 2006; Yip, 2004a) and among American Muslims (Minwalla et al., 2005) has recruited participants from gay Islamic support groups such as Al-Fatiha. IPT identifies group support (as social and informational networks and self-help groups) as a possible and effective intergroup strategy for coping with identity threat (Breakwell, 1986). Gay Islamic support groups essentially provide their members with a gay affirmative religious context which might in turn empower them to initiate discussion with the mainstream Muslim community (Siraj, 2006). In contrast, the participants in this study did not report any involvement in gay affirmative religious contexts and thus, the present paper provides novel insight into the cognitions and meaning-making of a group of BMGM outside of these supportive networks.

IPT will be used as an interpretive lens for the analysis of individuals' accounts of the construction of sexual identity and of the negotiation of this and other identities. Furthermore, since the existing literature suggests that BMGM (and other ethnic minority gay men) may experience identity threat as a result of their stigmatised sexual identities, this study explores some of the psychosocial strategies which may be employed by individuals to cope with identity threat. Thus, the objective of this study is two-fold; (i) to explore participants' lived experiences of managing their sexual, religious and ethnic identities; (ii) to advance IPT through its application in a fairly novel psychosocial context.

\section{Method}

\section{Participants}


A sample of twelve self-identified BMGM was recruited from the South Asian Community in a city in the East Midlands of England. The study focused solely upon the experiences of British-born self-identified Muslims of Pakistani heritage in order to recruit a more homogeneous sample, which was deemed important due to the sample size. Participants were male with a mean age of 22.2 years (SD: 1.3). Three participants were university students, four were college students, and the remaining five had GCSE/A-levels.

A snowball sampling strategy was employed, with the initial participants recruited through the first author's social networks. This allowed for the recruitment of participants with no involvement in gay affirmative religious contexts (e.g. support groups). The study was introduced to potential participants as one on 'being gay, Pakistani and Muslim'; thus, participants were recruited under these categories. The study was presented as an opportunity for individuals to discuss the general experiences associated with these identities in a non-judgmental, discreet, one-to-one setting. Furthermore, participants were informed that the results of the interview study would be to encourage further social psychological research on gay Muslims and to develop theory in this under-explored domain.

\section{Procedure and data generation}

The interviews were guided by a semi-structured interview schedule consisting of eleven exploratory, open-ended questions. The schedule began with questions regarding self-description and identity, followed by more specific questions on the perceived origin of their sexual identity; the construction of gay, religious and ethnic identities; the management of any difficulties arising from their multiple identities. Since one of the aims of the present research was to explore participants' meaningmaking vis-à-vis the interactions between their religious, ethnic and sexual identities, semi-structured interviews were preferred to questionnaires.

Participants were interviewed by a non-academic British Pakistani gay man in his early-twenties who wishes to remain anonymous. The interviewer was known to many of the participants who were also aware of the fact that he was Muslim and gay. Participants recruited through the snowball sampling strategy did not necessarily know the interviewer personally although they did know of him through friends. Interviews lasted between 60 and 90 minutes. They were digitally recorded by the interviewer and transcribed verbatim by the first author.

When the study was initially introduced to potential participants, it was highlighted that all participants would remain completely anonymous and that none of the statements made during interviews would be traceable to any individual. Given that none of the participants had disclosed their sexuality to family members, this guarantee of complete anonymity was pivotal for the recruitment of participants. Accordingly, pseudonyms have been used in this paper. Individuals were informed that they were under no obligation to answer all of the questions or to discuss 'uncomfortable issues'. Possibly due to the fact that interviews were conceptualised as 'discussions in a non-judgemental setting' rather than research interviews, participants appeared to feel comfortable and there was no opposition to any of the questions asked by the interviewer. Participants were reminded of their right to be fully debriefed after the interviews.

\section{Analytic approach}

The data were analysed using qualitative thematic analysis, which has been described as 'a method for identifying, analysing and reporting patterns (themes) within data' (Braun \& Clarke, 2006, p. 78). This approach was considered particularly useful since it allows the researcher to engage with theory in a quasi-deductive fashion in 
order to add theoretical depth to the data analysis (see Boyatzis, 1998; Hayes, 1997 for more on deductive approaches to qualitative research). Moreover, 'theoretical' thematic analysis allows for the generation of new theory and provides opportunities for developing models. Given the present study's aim to advance and to develop identity process theory, use of this particular method was considered highly advantageous. The study also aimed to capture participants' attempts to make sense of their personal and social worlds, with a particular focus on identities.

Given our research aim to explore participants' subjective experiences of being gay and Muslim and the various social and psychological meanings attached to these identities, this study adopts a realist epistemological approach to participants' accounts of their sexual identities. Thus, it views participants' talk as a fairly reliable reflection of their cognitions. The realist epistemological approach within thematic analysis allows the data analyst to theorise motivations, subjective experience, and meaning. This is important partly because this study endeavours to enhance one's understanding of the motivational principles of identity when identity is subjectively perceived by participants as being threatened. Furthermore, in order to understand the potential identity-threatening aspects of the intersection of gay and Muslim identities, it is necessary for the researcher to gain access to participants' subjective meaningmaking vis-à-vis their identities (Breakwell, 1986). Thus, the partial aim to advance identity process theory requires the ability to theorise motivations, experience and meaning. Thematic analysis allows for this level of analysis primarily because a largely unidirectional relationship is assumed to exist between language and cognition (Braun \& Clarke, 2006). In short, in this study language is viewed as a fairly accurate referential window into mind and cognition.

\section{Analytic procedures}

The recordings were transcribed by the first author, who also read the transcripts repeatedly in order to become as intimate as possible with the accounts. During each reading of the transcripts preliminary impressions and interpretations were noted in the left margin. These initial codes included inter alia participants' meaning-making, particular forms of language, and apparent contradictions and patterns within the data. Subsequently, the right margin was used to collate these initial codes into potential themes, which captured the essential qualities of the accounts. As highlighted by Braun and Clarke (2006, p. 82), 'a theme captures something important about the data in relation to the research question, and represents some level of patterned response or meaning within the data set.' Thus, the 'keyness' of the themes reported in the present study depended upon their importance in relation to the research questions. The themes were reviewed rigorously against the data in order to ensure their compatibility and numerous interview extracts were listed against each corresponding theme. It was at this stage that specific interview extracts, which were considered vivid, compelling and representative of the themes, were selected for presentation in the final research report. Finally, superordinate themes representing the themes derived from the 12 accounts were developed and ordered into a logical and coherent narrative structure.

In light of the convincing observation made by several researchers that interviews are interactional in nature (Potter \& Wetherell, 1995; Potter \& Hepburn, 2005), it was considered advantageous to include in this paper some of the more specific aspects of the interviewer's talk which may have prompted the interviewees' responses. It is felt that the provision of some of the surrounding talk, such as the interviewer's questions, allows for a more transparent analysis.

In the quotations from participants which are presented in the next section, two dots within square brackets indicate where material has been excised; other 
material within square brackets is clarificatory; text in italics are highlighted by the authors to illustrate their centrality in the discussion.

\section{Analysis}

\section{"I'm gay because..": Making sense of gay identity}

A central concern in this research was to explore participants' understandings and conceptualisations of their sexual identities, including the perceived origins of these identities and any sense of causality perceived to be underlying them. There was a tendency for participants to exhibit the dilemmatic qualities of their identities:

\footnotetext{
Sometimes I think it's wrong to be like this [gay] but then I guess I was born gay. It's the way I was born. Basically Allah [God] made me this way. It was his doing because as far back as I can think I've been this way, since I was a child, basically. (Ahmad)
}

The dilemma lies in individuals' perception that being gay is in some way 'wrong' or illicit but that, on the other hand, it is God who has created them 'this way'. This perhaps illustrates the general heteronormativity and compulsory heterosexuality prevalent in Muslim discourses (Kligerman, 2007). Moreover, this latter point and Ahmad's assertion that he has been gay 'as far back as I can think' indicates that being gay is an intrinsic aspect of his self-concept, one manifesting strong temporal continuity in the IPT sense, and not a development. At least three participants conceptualised their gay identities in essentialist terms by invoking similar discourses:

Interviewer: OK, right, so what do you get angry when your friends say that [that you are not a true Muslim]?

Jamal:It's not my fault God decided to make me gay, is it?

The data appear to permit two interpretations. Firstly, by invoking God as the creator, homosexuality cannot be viewed negatively since, if it were wrong this would presumably imply an element of imperfection in God. This could potentially threaten the continuity of their Muslim identity, which requires the belief in a perfect God (Beekun, 1996):

\section{He is a perfect creator (Jamal)}

The notion that this may pose a threat to continuity is further reinforced if one pays attention to the broader context of this interaction and the specific question asked. Jamal appears to employ this essentialist argument about the origins of his homosexuality when significant others (such as friends) call into question his authenticity as a religious ingroup member possibly in a bid to safeguard his sense of belonging in the religious ingroup (Vignoles et al., 2006). This perhaps highlights the importance of religious identity and a sense of belonging in the religious ingroup.

Secondly, by explaining his homosexuality in essentialist terms, as a result of God's decision-making, Jamal is able to eschew any sense of blame or personal responsibility (see Hegarty, 2002). This argument has been observed in recent sociological work on gay Muslims and gay Christians (Yip, 2007b) in which it has been asserted that individuals appropriate and reproduce such social representations in order to de-stigmatise their sexual identities. This is interesting at the theoretical level; while IPT argues that self-efficacy is an important identity principle 
(Breakwell, 1992), some participants come to perceive coherence and compatibility between their religious and sexual identities precisely because they perceive little or no self-efficacy vis-à-vis the development of their sexual identity. This perhaps indicates that gay identity among this particular sample may be less associated with the self-efficacy principle of identity; that is, this principle becomes less of a priority vis-à-vis the other principles (e.g. self-esteem, the need for a coherent sense of self).

Here it is argued that these data exemplify the deployment of an external attribution to explain the origins of sexual identity, which echoes Kelley's (1967, 1972, 1973) attribution theory. Identity process theory (IPT) identifies re-construal and re-attribution as possible deflection strategies associated with protection of the assimilation-accommodation process. Jamal and Ahmad appear to re-define the reason for being gay; it is not a sinful deviation of religious values, as the religious institution of Islam might suggest, but rather it is God's decision-making. Thus the participant comes to perceive those, who contest and problematise God's decision to create individuals who are gay, as sinners:

Interviewer: But how does that feel though [when you are threatened by non-gay Muslims]?

Ahmad: Like they're the ones sinning really, not me.

Interviewer: Really? In what way?

Ahmad: Why should I feel bad about it [being gay] though? Why would God do this for them [Muslims] to threaten me? (Ahmad)

This re-attribution (or external attribution) may benefit psychological well-being given that 'Islam forbids homosexual practices (..) regarding them a great sin' (Hewitt, 1997, p. 29). Accordingly, the deployment of this social representation may enable the individual to eschew the negative attribute 'sinner' and thus satisfy the IPT principle of self-esteem. More specifically, it seems that Ahmad reconceptualises the notion of sin; it is implied that those who threaten and menace gay Muslims, who themselves also constitute one of God's creations, are 'the ones sinning really'. IPT in particular helps to elucidate participants' meaning-making; this strategy of reconceptualising new incoming information is said to serve positive functions for identity (Breakwell, 1986). Accordingly, Ahmad is able to eschew the identity threatening position 'sinner' by redefining what constitutes a 'real' sin.

Furthermore, by professing a spiritual belief in Allah and by distancing themselves from the perceived hegemonic religious institution of Islam and from those associated with it, some participants were able to explain their sexual identities in divine terms.

Straight people, Muslim or not, just don't get it because they're not gay. But I know Allah loves me and that He is a perfect creator (Jamal)

Moreover, by highlighting the perfection of Allah and, by extension, the perfection of his creations, participants provided a fairly undilemmatic account of their (Islamic) spirituality and (gay) sexuality. Furthermore, it might be argued that psychologically the institution of Islam (religion) and personal belief in Allah (spirituality) are differentiated in some accounts. Loewenthal (1995) provides a similar distinction; she refers to spirituality as the belief in the existence of a non-material reality and to religion as being dependent upon social and institutional organisation. This differentiation between religion and spirituality is unusual in Islamic discourses since religion and spirituality are viewed as closely entwined (Ward, 2000; Rosowsky, 
2006). However, in Jamal's account this distinction seems to be necessary, psychologically, since on the one hand his account presents a critique of institutionalised religion and, on the other, it signals a spiritual attachment to Allah. In the absence of a formal distinction between the two forms of religiosity, criticism could give rise to a sense of psychological dissonance. Thus, a possible strategy to avoid this dissonance may be to re-conceptualise what it means to be Muslim and to ensure that the institutionalised and spiritual dimensions of Muslim identity are differentiated.

Moreover, in Jamal's above-cited account, homophobic representations in Islam are attributed to the inevitable misunderstandings which arise from human interpretation of the Koran, especially since the majority of those who have interpreted the Koran are 'straight people' who 'just don't get it'. This reflects some individuals' tendency to question the credibility of straight Muslims' interpretations of Koranic texts. This strategy of disputing the legitimacy of the exclusionary discourses employed by anti-gay Muslims perhaps safeguards individuals' sense of continuity as Muslim (Breakwell, 1986) and, crucially, a sense of coherence between sexual and religious identities.

In addition to questioning straight Muslims' interpretations of holy scripture, some individuals seemed to repudiate straight Muslims' rights to judge the morality of BMGM:

What right do they [straight Muslims] have to judge us [BMGM]? (Jamal)

Breakwell (1986) suggests that an individual with a threatened identity may acknowledge their position but deny that the position is in any way threatening, which according to IPT, constitutes a coping strategy. Here, however, there is no denial of the threatening position but rather Jamal questions straight Muslims' right to render this position threatening. There was a tendency for individuals to view this as unjust since they resented the notion that they (BMGM) were being represented by 'them' (straight Muslims) who could be considered an ingroup in terms of religious identity but as an outgroup in terms of sexual identity.

“It's all about temptation": Invoking religious discourses to explain sexual identity Unsurprisingly, not all participants re-conceptualised their Muslim identities in order to differentiate between the spiritual relationship with God and their involvement in the religious institution of Islam. This may be due to the implicit social expectation that all Muslims should participate in the wider religious community, e.g. by attending the local mosque for Friday prayers (Ward, 2000; Rosowsky, 2006). Aziz, who attached particular importance to participation in the wider Muslim community, was asked to reflect upon the perceived meanings of being gay:

Interviewer: OK, so earlier you were saying that being Muslim is a beautiful thing, and er how do you feel about being gay? I mean, what does it mean to you?

Aziz: It's wrong, really, isn't it?

Interviewer: Wrong? Why's that?

Aziz: In the mosque we're told that Shaitan [Satan] tries to tempt Muslims because he is evil and he makes us do evil things. I know that doing gay things is evil but I hope I'll change my ways and take the right path soon [..] It's all about temptation, really. Life is a big test. 
Here the interviewer prompts Aziz to provide some evaluative comments on his gay identity. The interviewer juxtaposes this with Aziz's earlier comments on his Muslim identity defined in highly positive terms. Aziz's response illustrates his dilemmatic relationship with his sexual identity in several important ways. On the one hand, he exhibits an awareness for the religious need to follow Allah and to reject Satan's attempts to deviate Muslims from 'the right path' but, on the other, he acknowledges his current inability to take this path due to temptation. Consequently, he clearly feels that it is his responsibility to change his homosexual behaviour. Moreover, it is interesting that Muslim identity seems to over-ride the potential for a mutual gay identity between interviewer and participant; despite both individuals' mutual selfidentification as gay, the participant seems to feel obliged to evaluate homosexuality in negative terms. The shared religious identity seems to take precedence here.

Furthermore, it is primarily through the (religious) lens of Islam, based upon sermons delivered in the mosque, that he attributes meaning to his sexual identity. However, it is acknowledged that this may partly be due to the interviewer's own juxtaposition of sexual and religious identities in his original question. In any case, this enables Aziz to attribute his gay tendencies to external religious sources; it is Satan that 'tempts' Muslims. Moreover, use of the verb 'makes' suggests little volition on the participant's part. This reiterates the aforementioned strategy of external attribution employed by participants to safeguard identity coherence. This seems to constitute a deflection strategy whereby Aziz attributes his gayness, which is attributed to Satan, to an 'unreal self' while being heterosexual represents a more desirable 'real self' (Breakwell, 1986).

Moreover, in Aziz's account, it seems that the institution of Islam, and not necessarily his personal, spiritual relationship with God, appears to affect adversely his ability to conceptualise his homosexual behaviour in terms of identity. Instead he appears to employ the deflection strategy of denial (of gay identity) to deal with the dilemma (Breakwell, 1986). This is evidenced by the fact that Aziz largely eschewed self-categorisation as 'gay' but rather reported 'doing gay things'. This seemed to enable him to disassociate 'doing gay things' from his self-concept and to encourage a psychological rapprochement between his self-concept and a more desirable 'future self': 'I hope I'll change'. Since identity was conceptualised by many individuals as 'everything that makes me who I am', self-categorisation as 'gay' (that is, by laying claim to a gay identity) might in fact pose a threat to the overall identity structure, in which religious identity is believed to be a central dimension (Jacobson, 1997; Jaspal $\&$ Coyle, 2010). However, it is likely that this would be relatively less problematic for those individuals who conceptualised their gayness in essentialist terms as a condition determined by Allah.

Similarly, for Aziz and most participants being Muslim seemed to constitute the most salient and meaningful dimension of their identities. A possible result of this was that all other identities were evaluated against religious criteria, that is, against Muslim identity. This process was by no means confined to the evaluation of sexual identity; for Aziz his religious identity had implications for his relationship with his ethno-national identity:

Interviewer: And what's [which identity] most important to you?

Aziz: Being a Muslim. That's my heart, my soul. I always try to be a good Muslim and sometimes it is hard but you got to try it.

Interviewer: Can you give me an example of this?

Aziz: Even on $14^{\text {th }}$ August [Pakistani independence day] I go out with my mates partying and sometimes I think 'This is wrong. Muslims are one.' 
Muslims aren't supposed to celebrate our national day because in Islam there's no nations.

It seems that Aziz's perpetual attempt 'to be a good Muslim' governs his evaluation of other potentially conflictual identities. His ethno-national identity as (British) Pakistani is problematised by his religious commitments, which reportedly outlaw any national (or ethnic) allegiances, which might undermine Islamic unity. This constitutes further evidence that his psychosocial world is perceived through a primarily religious lens. Given the ubiquity of religion in his general meaningmaking, it is unsurprising that he may experience considerable difficulty in accommodating his sexuality in his identity structure:

Maybe I'm not bisexual because I've never been with a woman but I can't call myself gay either [... I refuse to do that because I just don't feel gay (Aziz)

Like Aziz, other participants conceptualised their (homo)sexual behaviour as a temptation which was difficult to avoid and suppress:

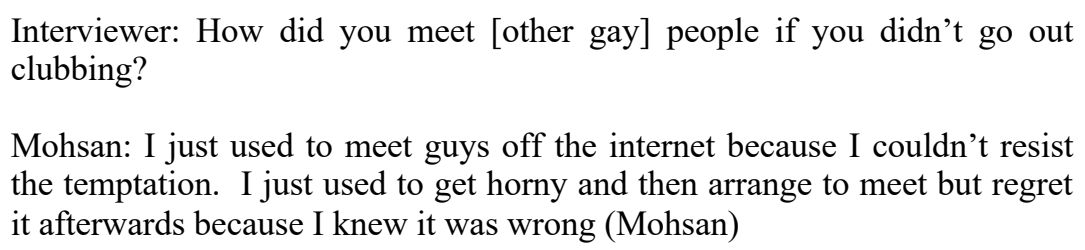

Despite the interviewer's specific interest in the formation and development of Mohsan's gay social networks, Mohsan continues to focus upon notions of temptation and regret. His conceptualisation of his gayness as a 'temptation' reiterates the aforementioned tendency among participants to invoke the Koran in making sense of gay identity. It has been noted that many LGB individuals who lay claim to a religious identity often provide alternative religious interpretations of homosexuality in order to reconcile their sexual and religious identities (Yip, 2005). However, the present findings suggest that some BMGM may refrain from re-interpreting or reconceptualising holy scripture and the perceived religious stance on homosexuality:

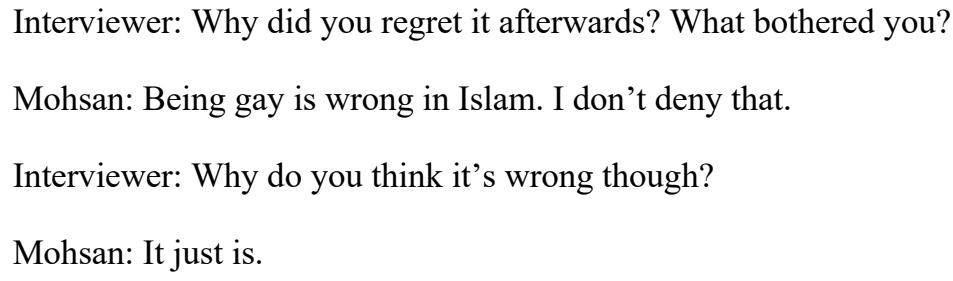

IPT identifies re-construal and re-interpretation as important strategies of coping with threat to identity (Breakwell, 1986). However, the interaction above attests to Mohsan's inability to provide a convincing explanation for believing in the sinfulness of homosexuality and illustrates his uncritical acceptance of this social representation (Breakwell, 2001; Jaspal \& Coyle, 2009). Like Mohsan, several individuals expressed their reluctance to re-conceptualise holy scripture, possibly due to their belief in its immutability:

What the Prophet said was right and that's always going to stand, yeah. Men having sex with other men was wrong in his eyes. He hated it (Rasool) 
Like the Koran is the only religious text that's not like changed, like the Bible and all that has been translated and changed and you don't know what it was supposed to be like saying originally (Jamal)

Thus, although theoretically the re-interpretation of holy scripture could potentially alleviate the threats posed to individuals' identity, as demonstrated in previous research (Yip, 2005), this strategy does not appear to be very appealing to some BMGM. Perhaps the re-interpretation of holy scripture might pose a threat to the continuity of their Muslim identity since participants had been socialised with a particular understanding of Islam as an immutable religion: 'that's always going to stand'. This point was reiterated by Jamal's proud observation that the Koran remained static and unchanged unlike Christian texts, for instance. Conversely, it could be argued that by re-interpreting holy scripture, individuals might safeguard psychological coherence by constructing their sexual and religious identities as compatible; indeed this has been identified as a possible coping strategy among LGB Christians and Muslims (Yip, 2005). However, conflicts between identity principles may arise and the principles achieve priority according to the social context (Breakwell, 1986; Vignoles, Chryssochoou \& Breakwell, 2000; Vignoles et al., 2002). In this particular context it would appear that the importance of the continuity of Muslim identity outweighs that of psychological coherence.

Nonetheless, some participants indeed exhibited their attempts to maintain psychological coherence between their sexual and religious identities by conferring value upon each one:

Interviewer: And how does that make you feel [that it is wrong]?

Rasool: Bad. It's wrong and I'm doing wrong. I need to be a better Muslim.

Interviewer: And what does it mean to be a better Muslim?

Rasool: Well not gay for starters.

Rasool's account signalled a sense of guilt arising from the combination of his sexual and religious identities, and indeed this has been observed in previous work on the interface between gay and religious identities (Thumma, 1991; Siraj, 2006). However, the important point is that one identity is evaluated positively (being a Muslim) and the other as 'wrong' (being gay). Indeed, 'a better Muslim' is perceived as one who is not gay, which implicitly construes gayness as a barrier to the authenticity and quality of one's Muslim identity. Several individuals identified a further strategy for coping with their antagonistic sexual and religious identities:

Interviewer: Alright so if it's a sin so what's like what's going to happen to someone who is gay and Muslim at the same time?

Aziz: I don't know, yeah, but bottom line is Allah loves us and I know that as a Muslim I'll go to heaven. 'Compassionate' is one of his 100 names. (Aziz)

While Aziz expresses some doubt regarding the possible outcomes for a gay Muslim in the afterlife, there is no attempt to refute the sinfulness of homosexuality in Islam. Breakwell (2001) has noted that individuals might re-construe and personalise social representations in order to enhance the identity principles. Despite the potential benefits that strategies of denial or re-construal could have for identity, Aziz seems to accept the social representation that homosexuality is indeed sinful. This may be because of the pervasiveness and dominance of the social representation, which is 
thus difficult to re-construe and personalise despite the potentially negative consequences for identity principles (see Jaspal \& Coyle, 2009). Furthermore, Aziz does not deny his gay identity. Rather he emphasises one of the attributes of Allah, namely 'compassion' which indicates his belief (or hope?) that he will be forgiven for being gay. It is clearly his identity as a Muslim which takes precedence over all other identities, as exemplified by his account of Pakistan national independence day.

\section{“Going against God": Fear of divine retribution}

For some participants homosexuality was conceptualised as a temptation which was difficult to suppress. It was common for many participants to evaluate their sexual behaviour negatively or, as Aziz's account demonstrated, to inculpate a source greater than humankind such as Satan. This latter strategy may be particularly useful since it incorporates a theological explanation. It is noteworthy that Islamic teachings are particularly explicit in their condemnation of homosexuality, which has left little possibility for theological accommodation (Duran, 1993). Furthermore, one might view this as an additional example of external attribution since the individual continues to eschew any sense of personal responsibility. Although such explanations perhaps allowed participants to provide a coherent explanation for their (sexual) identities, it did not appear to have particularly positive psychological outcomes since there remained an acknowledged dissonance between their own behaviour and that prescribed by their religion:

\footnotetext{
Mohsan: Being gay goes against Islam completely, I know, but I try to resist it. I want to get married some day.

Interviewer: Do you think you'll be able to?

Mohsan: I don't know. I hope so because right now I'm going against God
}

It was clear that this perceived dissonance had particularly negative outcomes for one participant's psychological well-being. Participants were systematically asked how they felt about their gay identities. In response to this question, Aziz seemed to perceive his sexual identity in terms of a psychological burden: 'always hanging over me'. To illustrate this point Aziz recounted his experience of going to Heaven (a gay nightclub in London) for the first time with his ex-partner:

Interviewer: And how do you feel about that [being gay]? I mean, is it a big
part of you?

Aziz: Yeah, it is. It's always there right, always hanging over me.

Interviewer: In what way?

Aziz: Well [..] I sat down [in Heaven] and I kept thinking the roof was going to fall in any minute and that we'd all die there and then [..] I knew it was a bad place with bad stuff going on around me. I hated that night.

Despite Aziz's 'confession' that he was contravening his religious obligations to resist the temptation of Satan and his explanation for his wrong-doing, he was unable to escape the psychological tension arising from his knowledge of his homosexual behaviour. Furthermore, Aziz's conceptualisation of life, and by extension of his sexuality, as 'a big test' in fact appears to aggravate the fear of divine retribution associated with living a gay lifestyle. This fear was also reflected in Mohsan's account in which he indicated that his gay identity problematised the authenticity of his Muslimness and introduced the possibility of divine retribution: 
Interviewer: So how is that [being gay] affected by being a Muslim? Like I mean, if you're a Muslim, you're going to heaven anyway, right?

Mohsan: Yeah, all Muslims go to heaven. But if I'm gay am I acting like a true Muslim? That's the question. And if I don't then, yeah, then you go to hell.

\section{"It's easier to be gay here": External attributions and British national identity}

Participants who attached less importance to their religious identities were, nonetheless, subject to the conservatism of their ethnic culture. Pakistani lifestyles and social values are not conducive to gay identity (Khan, 1997). This became apparent in participants' responses to questions regarding their perceptions of the 'origins' of their homosexuality. For instance, having been socialised in Pakistani ethnic culture, Sajid provided an account of his sexuality in which he blamed an ethno-national outgroup:

Interviewer: There's been some debate, hasn't there, on er the nature or nurture story of homosexuality. What do you think about that?

Sajid: I don't think you're born gay [..] No, I don't believe that.

Interviewer: So it's about nurture?

Sajid: Yeah, I'm gay because I was brought up here [in Britain] but I reckon if I'd been brought up in Pakistan then I would have turned out straight because this doesn't happen that much there. Like I haven't heard of any gays in our village. Here there are clubs and that and so I just kind of fell into the gay culture.

Although this particular explanation for one's sexuality was uncommon in this sample of participants, it was deemed an interesting one to elaborate since it exemplifies the common theme of external attribution which characterised many participants' accounts. It exhibits an additional strategy of making sense of gay identity, as reiterated by Mo:

Interviewer: So you think you were born gay?

Mo: For sure, yeah, but people can change too [...] You see it all the time on TV [..] It's easier to be gay here [in Britain] and I bet there are people in Pakistan who know they like lads but just don't act on it because they can't really

Interviewer: And if you can't like act on it does it mean you're not gay or are you gay or something else?

Mo: I don't know really. But here you've got your clubs right so it's like you can be gay if you want to and you can become a gay person and like marry [another man], then you're gay for real [..] But like I'm going to marry a girl eventually.

Sajid views his sexuality as a mutable identity which is dependent primarily upon the socio-cultural context; due to the presence of 'gay culture' in the national context he is able to 'fall' into this perceived subculture. There are clear processes of 'othering' at work here; by employing unitary and monolithic terms such as 'gay culture' Mo seems to essentialise and homogenise gay individuals who are clearly perceived as being 'other' to himself. They are 'other' to him as he views himself as 'less gay' 
due to his intention to marry a woman vis-à-vis their tendency to marry other men. Yip (2004a, p. 340) notes that homosexuality is widely perceived amongst parents within the Muslim community as a 'western disease', which implies that to be gay and Muslim is the result of 'being intoxicated by secular Western culture'. However, Sajid's account demonstrates that this notion is by no means confined to parents but rather that it may be invoked by BMGM themselves in making sense of their sexual identities. Making this external attribution perhaps enables individuals to preclude beliefs of personal blame and guilt and thereby enables them to safeguard a sense of self-esteem (Breakwell, 1986).

For others, Britain condones and perhaps encourages gay lifestyle:

\author{
Interviewer: How is it [being gay] easier though? \\ Mo: Well, you know, gays have got rights and you can get done for \\ homophobia and that. \\ Interviewer: Is that a good thing or a bad thing? \\ Mo: It's kind of like encouraging you to be gay, I reckon. It doesn't feel \\ wrong for White people I bet because yeah, that's it.
}

Mo's account seems to imply that leading a gay lifestyle and identification as gay are much easier within the British context. Moreover, the freedom of sexual orientation is perceived by Mo as an encouragement for individuals to identify as gay. It is implied that this may constitute one reason for 'acting on it', that is, one's gay identity. Therefore, like Aziz, Mo conceptualises sexuality in behavioural terms; being gay is defined as engaging in homosexual behaviour or 'doing gay things'. Moreover, this behaviour, which Mo had constructed as wrong and un-Islamic, is viewed as being tolerated and even endorsed by White people.

British endorsement of gay rights and of legislation which safeguards these rights appears to play a role in Mo's meaning-making vis-à-vis the construction of gay identity. Since Sajid and Mo allude to a sense of perceived choice in the being gay, they also express the belief that factors such as the national context play an instrumental role in the construction of gay identity. Given the negative social representations surrounding Britishness and the cultural norms viewed as being associated with Britishness, which are prevalent among South Asian communities (Ballard, 1994; Shaw, 1994), especially within the domain of morality, it is perhaps not surprising that some participants may deploy the argument that their homosexuality arises from their socialisation within the perceived cultural context of the national outgroup.

\title{
Discussion
}

The present article exhibits some of the difficulties which may be experienced by BMGM in constructing their sexual identities and in attempting to reconcile their seemingly incongruous sexual and ethno-religious identities. Moreover, it identifies strategies which may be employed to cope with the psychosocial difficulties associated with these processes.

It has been argued that identity process theory (IPT) provides a particularly useful framework for interpreting identity threat as experienced by BMGM and for understanding the strategies employed to manage and reconcile their sexual and religious identities. Unlike many competing theoretical frameworks, IPT recognises that identity can function at different levels (i.e. intrapsychic, interpersonal, intergroup), although it does not advocate a dichotomous split between personal and social identities (Breakwell, 2001). Moreover, Breakwell's (1986, 1992) theorising 
on the motivational principles allowed for a more thorough understanding of experiences of identity threat among BMGM, and since this list of principles is neither exhaustive nor cross-culturally universal, there is scope for the development of additional identity principles which might guide identity processes. This latter point is evidenced by work by Vignoles et al. $(2002,2006)$ and by the present paper. Furthermore, the present research elucidates how identity principles may relate to one another in dilemmatic situations with potential for conflict between them and particularly how and why one principle may be given priority over another. For instance, gay identity among BMGM seemed to be less associated with self-efficacy than with other identity principles. This paper seeks to develop IPT but it also argues that the predictions associated with the theory provide the interpretive tools required to understand identity threat at the intrapsychic level, which is a key aspect of this paper, as well as some of the cognitive coping strategies activated in order to alleviate identity threat.

In their attempts to make sense of their sexual identities, the majority of individuals exhibited feelings of guilt and wrong-doing when exploring the origins of their sexualities. This may be attributed to the widespread tendency among participants to view their sexual, and other, identities primarily through a religious lens. Consequently, individuals seemed to evaluate the content of their (sexual) identities against religious criteria; in many cases, this posed immense difficulties for the reconciliation of religious and sexual identities. Some individuals perceived dissonance between behaviour prescribed by holy scripture and their own (sexual) behaviour. Consequently, some participants, for instance, expressed fear of inescapable divine punishment, which often presented obstacles for everyday life (e.g. involvement in gay nightlife).

\section{External attribution}

Amid their feelings of guilt and wrong-doing, participants frequently invoked external causal factors as underlying their sexual orientations. Accordingly, they rejected any personal responsibility for, or agency in, their sexual identities, but instead argued that they were born gay and should, therefore, laud God's creation. Thus, causality was attributed to God and not to themselves. On the other hand, homosexuality was conceptualised by many individuals as a deviation from 'the right path' prescribed by their religious beliefs and, in some cases, as a Satanic attempt to turn them away from God. The latter point exhibits an additional manner in which religious individuals may attribute their sexual orientation to an external causal factor. It is constructed as Satan's doing, not theirs.

Furthermore, the notion of external attribution was observable in the interface of ethno-religious and national identities vis-à-vis sexual identity. Possibly because morality and moral values are perceived as being closely related to ethnic culture (Phinney, 1996), at least one participant viewed British national culture as one of the possible causal factors underlying gay identity. This was perhaps facilitated by the negative social representations of Britishness and associated cultural norms, which have been observed among members of the South Asian community (Ballard, 1994). Thus, gay identity was attributed to the (external) socio-cultural environment which, thereby, enabled them to eschew personal responsibility for their own behaviour and identities. Instead the ethno-national outgroup and their culture were inculpated. However, it is noteworthy that while individuals frequently rejected personal responsibility for, or agency in, their sexual orientation/ identity, they did claim to be in control of and, in many cases, responsible for their sexual behaviour. The knowledge of this could be fairly threatening for psychological coherence and thus identity in general. 


\section{Towards an additional identity principle: Psychological coherence}

The pervasive tendency for participants to identify external factors as causal perhaps indicates their need for coherence between salient religious identities and their gay behaviour/ identities. Social psychologists have alluded to the need for (identity) coherence through the development of theories to explain individuals' attempts to avoid cognitive dissonance (Festinger, 1957; Festinger \& Carlsmith, 1959; Abelson et al., 1968). Others (Tajfel, 1969; Steele, 1988) have been more explicit in noting that coherence enables individuals to preserve self-integrity, although this issue has received little empirical attention. More recently, Roccas and Brewer (2002, p. 93) have proposed the notion of social identity complexity, whereby 'high complexity involves acknowledgement of differentiation and difference between ingroup categories'. Like Tetlock (1986), they assume that 'high complexity' requires effortdemanding cognitive strategies. While their analysis focuses upon the cognitive consequences of 'high complexity', the present study provides some insight into the consequences of multiple, conflicting identities for participants' psychological and emotional well-being.

The data presented in this paper suggest the existence of an additional identity principle, namely the need for psychological coherence. It is noteworthy that the psychological coherence principle is markedly distinct from Breakwell's (1986) continuity principle. While continuity denotes a temporally coherent and continuous sense of self, especially in light of sudden events or experiences (Breakwell, 1986), the psychological coherence principle refers to the need for compatibility and coherence between pre-existing identities - i.e. between different constituent elements of the self-concept. Many participants laid claim to a sexual identity (gay) as well as a religious identity (Muslim) and, in many cases, these identities were constructed as being primordial in the self-concept: 'as far back as I can remember I've been this way'. Thus, the struggle was not necessarily to maintain a sense of continuity either as Muslim or as gay but rather to reconcile the incoherent pre-existing identities.

In the present paper the meaning of psychological coherence is very specific; it refers to the individual's subjective perception of compatibility between their identities. We do not argue that individuals agonise about the compatibility of each identity they possess; rather, some identities will be perceived to be indifferent and unconnected, whereas others will be perceived to be interconnected (see Hofman, 1988), and it is the latter that we are concerned with. Building upon the aforementioned work, the present research highlights the importance of the psychological coherence principle and proposes that it be incorporated in the IPT framework. This may be more beneficial than separate theorising about individual identity principles. In this study, the psychological coherence principle manifests itself primarily as guiding the evaluation process of identity. For instance, since sexual and religious identities were viewed as incoherent and incompatible, there seemed to be a tendency among some participants to attach negative value and meaning to their sexual identity. On the other hand, some participants appeared to confer negative value to the institutional component of religious identity and to attach more positive value and meaning to the spiritual dimension of religious identity.

Although BMGM varied in their allocation of meaning and value to distinct identities, the basic aim remained the same; individuals made attempts to maintain psychological coherence by denigrating one of the two identities. Interestingly, some participants, through their deployment of external attributions for their gay behaviour (e.g. they were tempted by Satan), apparently managed to reduce the potential psychological costs of perceiving their sexual identity as negative and incompatible with their valued religious identity. This illustrates an important point - that 
psychological coherence is in the eye of the perceiver and not some objective quality of the identities under scrutiny; thus, although any individual will be influenced by the prevailing social representations of the identities in question, they can arrive at their own conclusion about their ultimate compatibility. Our conceptualisation of the coherence principle is thus more complex than traditional psychological constructs of cognitive dissonance and the process of dissonance reduction, since we argue that coherence is achieved by both intra-psychic coping strategies and an awareness of broader intergroup issues which include the social representations endorsed and disseminated by relevant social groups.

\section{Coping strategies}

The quest for psychological coherence seemed pervasive and the strategies employed varied. Some individuals eschewed self-categorisation as 'gay' but rather conceptualised their homosexuality in primarily behavioural terms. While this appeared to safeguard the psychological coherence of their identities, there was nonetheless a perceived dissonance between sexual behaviour and religious identity. There was a tendency among these individuals to perceive and to conceptualise their sexual behaviour as a 'mistake' whose origins were nonetheless external.

On the other hand, those individuals, who appeared to be at ease with their gay identity, often prioritised their personal, spiritual relationship with God, which in turn seemed to obviate difficulties perceived as originating from the religious institution of Islam. A clear distinction was made between spirituality, associated with (a perfect) God, and religion, which was perceived as being prescribed by generations of human beings who had misinterpreted, and thus misrepresented, God's word. In line with IPT, this perhaps reflected attempts to re-conceptualise what it meant to be Muslim (Breakwell, 1986). This in turn enabled individuals to reconcile their spiritual and sexual identities in a fairly unproblematic manner and thus to maintain a sense of psychological coherence.

Coping with their stigmatised identities seemed to have consequences for the social group. Some accounts appeared to problematise religious group dynamics with a re-conceptualisation of ingroup/outgroup boundaries. Since there were attempts to repudiate the 'right' of the religious institution (which was viewed as consisting entirely of heterosexual Muslim men) to judge homosexuals and to establish the boundaries of morality, it seemed that ingroup/outgroup boundaries were revised to the extent that heterosexual Muslim men's 'jurisdiction' over BMGM was questioned. This not only questioned what it meant to be Muslim but also who had the right to question BMGM's religious identity and sense of morality. Thus, in the context of sexual identity 'we' referred to BMGM whereas 'they' denoted heterosexual Muslim men; in this respect, BMGM identity seemed to differ significantly from Muslim identity in general. Accordingly, the repudiation of the religious institution may constitute a strategy to protect psychological coherence. Being gay and Muslim may be viewed as incoherent insofar as individuals confer upon the religious institution the right to make this ruling.

However, the strategy of repudiating the religious institution was not embraced by all participants, many of whom attached particular importance to institutional Islam. For these individuals, the re-construal and re-conceptualisation of holy scripture to reconcile it with their sexual identities was not perceived as an option (cf. Yip, 2005). While, theoretically, this deflection strategy might have benefited psychological coherence, since it could reduce dissonance between their religious and sexual identities, it could in turn have negative consequences for individuals' sense of continuity (Breakwell, 1986). This may be because the immutability of Islam and holy scripture seemed to form part of their belief system. 
Thus, it is unclear how the identity principles relate to one another and how potential conflicts between them might be resolved by individuals. This undoubtedly merits attention in future research.

\section{Conclusion}

The present paper employs identity process theory to provide insight into the experiences of a group of BMGM in non-gay affirmative religious contexts and the psychosocial processes underlying their identities and experiences. The intersection of religious, ethnic and sexual identities in this particular sample has been said to give rise to identity threat, and in some cases national identity may be invoked in order to alleviate this threat. In addition to six aforementioned identity principles outlined in IPT, psychological coherence is proposed as an additional principle which may have some motivational force in guiding identity processes. Accordingly, it is suggested that the obstruction of this and other principles may give rise to identity threat and that individuals will employ various coping strategies, such as external attribution and revision of group dynamics, in order to expunge the threat (Breakwell, 1986; Jaspal \& Coyle, 2009). The present paper provides some preliminary insight into identity processes among BMGM and it is hoped that future research will seek to extend and validate the theoretical developments reported here through the use of other methodologies and in other cultural contexts.

\section{Acknowledgements}

The authors would like to thank Catherine Amiot, Richard Y. Bourhis and Roxane de la Sablonnière for their comments on psychological coherence. They would also like to thank three anonymous reviewers who provided insightful comments on an earlier version of the manuscript. This paper has also benefited from useful comments from Elizabeth Stokoe.

\section{References}

Abelson, R.P., Aronson, E., McGuire, W.J., Newcomb, T.M., Rosenberg, M.J. \& Tannenbaum, P.H. (1968). Theories of Cognitive Consistency: A Sourcebook. Chicago: Rand McNally.

Amiot, C.E., de la Sablonnière, R., Terry, D.J. \& Smith, J.R. (2007). Integration of Social Identities in the Self: Toward a Cognitive-Developmental Model. Personality and Social Psychology Review, 11, 364-88.

Ballard, R. (1994). Introduction: The emergence of Desh Pardesh. In R. Ballard (Ed.), Desh Pardesh: The South Asian Experience in Britain (pp.1-35). London: C. Hurst \& Co.

Baumeister, R.F. (1986). Identity: Cultural change and the struggle for self. Oxford: Oxford University Press.

Beekun, R.I. (1996). Islamic Business Ethics. Herndon, VA: International Institute of Islamic Thought.

Benet-Martinez, V. \& Haritatos, J. (2005). Bicultural identity integration (BII): Components and psychological antecedents. Journal of Personality, 73, 10151050 .

Benet-Martinez, V., Lee, F. \& Leu, J. (2006). Describe your culture: Cultural representations in biculturals. Journal of Cross Cultural Psychology, 37, 386407.

Boellstorff, T. (2005). Between religion and desire: Being Muslim and gay in Indonesia. American Anthropologist, 107, 4, 575-585. 
Bouhdiba, A. (1998). Sexuality in Islam. London: Saqi Books.

Boyatzis, R.E. (1998). Transforming qualitative information: thematic analysis and code development. London: Sage.

Braun, V. \& Clark, V. (2006). Using thematic analysis in psychology. Qualitative Research in Psychology, 3, 77-101.

Breakwell, G.M. (1986). Coping with Threatened Identities. London: Methuen.

Breakwell, G.M. (1988) Strategies adopted when identity is threatened. Revue Internationale de Psychologie Sociale, 1, 189-204.

Breakwell, G.M. (1992). Processes of Self-Evaluation: Efficacy and Estrangement. In: Breakwell, G.M. (Ed.), Social Psychology of Identity and the Self Concept (pp.335-355). London: Academic Press/Surrey University Press.

Breakwell, G.M. (1993). Social Representations and Social Identity. Papers on Social Representations, 2, 198-217.

Breakwell, G.M. (2001). Social representational constraints upon identity processes. In K. Deaux \& G. Philogene (Eds.), Representions of the Social: Bridging Theoretical Traditions (pp.271-284). Oxford: Blackwell.

Brewer, M.B. (1991). The social self: on being the same and different at the same time. Personality and Social Psychology Bulletin, 17, 475-482.

Campbell, J.D., Assanand, S. \& Di Paula, A. (2003). The structure of the self-concept and its relation to psychological adjustment. Journal of Personality, 71(1), $115-40$.

Cheng, C., Sanders, M., Sanchez-Burks, J., Molina, K., Lee, F., Darling, E \& Zhao, Y. (2008). Reaping the rewards of diversity: The role of identity integration. Social and Personality Psychology Compass, 2, 1182-92.

Coyle, A. (1991). The Construction of Gay Identity. Unpublished doctoral dissertation, University of Surrey, Guildford, UK

Coyle, A. \& Rafalin, D. (2000). Jewish gay men's accounts of negotiating cultural, religious and sexual identity: A qualitative study. Journal of Psychology and Human Sexuality, 12, 21-48.

Duran, K. (1993). Homosexuality in Islam. In A. Swidler (Ed.), Homosexuality and World Religions (pp.181-198). Harrisburg, PA: Trinity Press.

Festinger, L. (1957). A Theory of Cognitive Dissonance. Stanford, CA: Stanford University Press.

Festinger, L. \& Carlsmith, J.M. (1959). Cognitive consequences of forced compliance. Journal of Abnormal and Social Psychology, 58, 203-210.

Green, M.C. \& Numrich, P. (2001). Religious Perspectives on Sexuality: A Resource Guide. Chicago: The Park Ridge Center.

Harter, S., \& Monsour, A. (1992). Developmental analysis of conflict caused by opposing attributes in the adolescent self-portrait. Developmental Psychology, $28,251-260$.

Hayes, N. (1997). Theory-led thematic analysis: social identification in small companies. In N. Hayes (Ed.), Doing qualitative analysis in psychology. Psychology Press.

Hegarty, P. (2002). "It's not a choice, it's the way we're built": Symbolic beliefs about sexual orientation in the US and Britain. Journal of Community and Applied Social Psychology, 12, 153-166.

Hewitt, I. B. (1997). What does Islam Say? London: Muslim Education Trust.

Higgins, E.T. (1991). Development of self-regulatory and self-evaluative processes: Costs, benefits, and tradeoffs. In M. R. Gunnar \& L. A. Sroufe (Eds.), Self processes and development: The Minnesota Symposium on Child Development (Vol. 23, pp. 125-166). Hillsdale, NJ: Lawrence Erlbaum. 
Hitlin, S. (2003). Values as the core of personal identity: Drawing links between two theories of self. Social Psychology Quarterly, 66(2), 118-37.

Hofman, J.E. (1988). Social identity and intergroup conflict: an Israeli view. In W. Stroebe, A.W. Kruglanski, D. Bar-Tal and M. Hewstone (Eds.), The Social Psychology of Intergroup Conflict (pp.80-102). New York: Springer Verlag.

Jacobson, J. (1997). Religion and ethnicity: dual and alternative sources of identity among young British Pakistanis. Ethnic and Racial Studies, 20, 238-256.

Jaspal, R. \& Coyle, A. (2009). Language and perceptions of identity threat. Psychology and Society, 2(2), 150-167

Jaspal, R. \& Coyle, A. (2010). "Arabic is the language of the Muslims - that's how it was supposed to be": exploring language and religious identity through reflective accounts from young British-born South Asians. Mental Health, Religion and Culture, 13(1), 17-36.

Kelley, H.H. (1967). Attribution theory in social psychology. In D. Levine (Ed.), Nebraska Symposium on Motivation (Vol. 15, pp.192-238). Lincoln, NE: University of Nebraska Press.

Kelley, H.H. (1972). Causal schemata and the attribution process. In E.E. Jones, D.E. Kanouse, H.H. Kelley, R.E. Nisbett, S. Valins \& B. Weiner (Eds.), Attribution: Perceiving the Causes of Behavior (pp.151-174). Morristown, NJ: General Learning Press.

Kelley, H.H. (1973). The processes of causal attribution. American Psychologist, 28, 457-501.

Khan, B. (1997). Not-so-gay life in Pakistan in the 1980s and 1990s. In S.O Murray \& W. Roscoe (Eds.), Islamic Homosexualities: Culture, History and Literature (pp.275-296). New York: New York University Press.

Kligerman, N. (2007). Homosexuality in Islam: A difficult paradox. Macalester Islam Journal, 2(3), 55-64.

Loewenthal, K.M. (1995). Religion and Mental Health. London: Chapman \& Hall.

Markowe, L.A. (2002). Coming out as a lesbian. In A. Coyle \& C. Kitzinger (Eds.), Lesbian and Gay Psychology: New Perspectives (pp.63-80). Oxford: BPS Blackwell.

Marques, J., Yzerbyt, V., \& Leyens, J.-P. (1988). The 'Black Sheep Effect': Extremity of judgments toward ingroup members as a function of group identification. European Journal of Social Psychology, 18, 1-16.

Minwalla, O., Rosser, B.R.S., Feldman, J. \& Varga, C. (2005). Identity experience among progressive gay Muslims in North America: a qualitative study. Culture, Health and Sexuality, 7, 113-128.

Murray, S.O. (1997). Male actresses in Islamic parts of Indonesia and the Southern Philippines. In S.O Murray \& W. Roscoe (Eds.), Islamic Homosexualities: Culture, History and Literature (pp.256-261). New York: New York University Press.

Phellas, C.N. (2005). Cypriot gay men's accounts of negotiating cultural and sexual identity: a qualitative study. Qualitative Sociology Review, 1(2), 6583.

Phinney, J.S. (1993). Multiple group identities: Differentiation, conflict, and integration. In J. Kroger (Ed.), Discussions on ego identity (pp. 47-73). Mahwah, NJ: Lawrence Erlbaum.

Phinney, J.S. (1996). When we talk about American ethnic groups, what do we mean? American Psychologist, 51, 918-927.

Potter, J. \& Hepburn, A. (2005). Qualitative interviews in psychology: Problems and possibilities. Qualitative Research in Psychology, 2, 281-307. 
Potter, J. \& Wetherell, M. (1995). Discourse analysis. In J. Smith, R. Harré, \& L. van Langenhove (eds.), Rethinking methods in psychology (pp.80-92). London: Sage.

Roccas, S. \& Brewer, M. B. (2002) Social identity complexity. Personality and Social Psychology Review, 6, 88-106.

Rosowsky, A. (2006) The role of liturgical literacy in UK Muslim communities. In T. Omoniyi \& J. A. Fishman (Eds.), Explorations in the Sociology of Language and Religion (pp.309-324). John Benjamins. Amsterdam.

Shaw, A. (1994). The Pakistani Community in Oxford. In R. Ballard (Ed.), Desh Pardesh: The South Asian Experience in Britain (pp.36-57). London: C. Hurst \& Co.

Silberman, I. (2005). Religion as a Meaning System: Implications for the New Millennium. Journal of Social Issues, 61, 641-663.

Simon, B. (2004). Identity in Modern Society: A Social Psychological Perspective. Oxford: Blackwell Publishing Ltd.

Siraj, A. (2006). On being homosexual and Muslim: Conflicts and challenges. In L. Ouzgane (Ed.), Islamic Masculinities (pp.202-216). London: Zed Books.

Steele, C. M. (1988). The psychology of self-affirmation: Sustaining the integrity of the self. In L. Berkowitz (Ed.), Advances in Experimental Social Psychology (Vol. 21, pp.261-302). San Diego, CA: Academic Press.

Tajfel, H. (1969). Cognitive aspects of prejudice. Journal of Social Issues, 25, 79-97. Tajfel, H. (1978). Differentiation between Social Groups. London: Academic Press.

Tajfel, H. (1981). Social stereotypes and social groups. In J. C. Turner \& H. Giles (Eds.), Intergroup Behaviour (pp. 144-167). Oxford, UK: Basil Blackwell.

Tetlock, P.E. (1986). A value pluralism model of ideological reasoning. Journal of Personality and Social Psychology, 50, 819-827.

Thumma, S. (1991). Negotiating a religious identity: The case of the gay Evangelical. Sociological Analysis, 52, 333-347.

Verkuyten, M. (2005). The Social Psychology of Ethnic Identity. Hove: Psychology Press.

Vignoles, V. L., Chryssochoou, X., \& Breakwell, G. M. (2000). The distinctiveness principle: Identity, meaning and the bounds of cultural relativity. Personality and Social Psychology Review, 4, 337-354.

Vignoles, V. L., Chryssochoou, X., \& Breakwell, G. M. (2002). Evaluating models of identity motivation: Self-esteem is not the whole story. Self and Identity, 1, 201-218.

Vignoles, V.L., Regalia, C., Manzi, C., Golledge, J. \& Scabini, E. (2006). Beyond self-esteem: Influence of multiple motives on identity construction. Journal of Personality and Social Psychology, 90, 308-333.

Vugt, V.M. \& Hart, C.M. (2004). Social identity as social glue: The origins of group loyalty. Journal of Personality and Social Psychology, 86, 585-598.

Ward, K. (2000). Religion and Community. Oxford: Clarendon Press.

Yip, A.K.T. (1997). Gay Male Christian Couples. Westport, CT: Praeger.

Yip, A.K.T. (2004a). Negotiating space with family and kin in identity construction: the narratives of British non-heterosexual Muslims. The Sociological Review, 52, 336-350.

Yip, A.K.T. (2004b). Embracing Allah and sexuality? South Asian non-heterosexual Muslims in Britain. In K.A. Jacobsen \& P.P. Kumar (Eds.), South Asians in the Diaspora: Histories and Religious Traditions (pp. 294-310). Leiden: Brill.

Yip, A.K.T. (2005). Queering religious texts: An exploration of British, nonheterosexual Christians' and Muslims' strategy of constructing sexualityaffirming hermeneutics. Sociology, 39, 47-65. 
Yip, A.K.T. (2007a). Sexual orientation discrimination in religious communities. In M.V.L. Badgett \& J. Frank (Eds.), Sexual Orientation Discrimination: An International Perspective (pp. 209-244). London: Routledge.

Yip, A.K.T. (2007b). Changing Religion, Changing Faith: Reflections on the Transformative Strategies of Lesbian, Gay, and Bisexual Christians and Muslims. The Journal for Faith, Spirituality and Social Change, 1(1), 83-95. 